\title{
Refractory Pulmonary Interstitial Emphysema in Extreme Premature Newborn
}

\author{
Mahmoud Ali, MBBCH ${ }^{1} \quad$ Lea Mallett, $\mathrm{PhD}^{1} \quad$ Greg Miller, MD ${ }^{1}$ \\ ${ }^{1}$ Department of Pediatrics, Texas A\&M Health Science Center, Baylor \\ Scott \& White McLane Children's Medical Center, Temple, Texas \\ Am J Perinatol Rep 2021;11:e61-e64.

\begin{abstract}
Address for correspondence Mahmoud Ali, MBBCH, Department of Pediatrics, Texas A\&M Health Science Center, Baylor Scott \& White McLane Children's Medical Center, 1901 Southwest HK Dodgen Loop, Building 300, MS-CK-300, Temple, TX 76502
\end{abstract} \\ (e-mail: Mahmoud.Ali@BSWHealth.Org).
}

\author{
Abstract \\ Keywords \\ - pulmonary interstitial \\ emphysema \\ - air leak syndrome \\ - prematurity \\ - respiratory distress \\ - selective intubation
}

Pulmonary interstitial emphysema (PIE) occurs when air leaks into the pulmonary interstitium due to overdistension of distal airways, it occurs mainly in neonates with respiratory distress syndrome who need positive pressure ventilation but has also been reported in spontaneously breathing infants. Herein, we report on an extremely low birth weight infant with severe persistent PIE, while on invasive mechanical ventilation (high-frequency oscillatory ventilation, high-frequency jet ventilation, and neurally adjust ventilator assist) managed successfully with 2 weeks of selective right lung ventilation after failure of more conservative measures, including shorter periods of right mainstem intubation, before the prolonged trial that was successful.
Pulmonary interstitial emphysema (PIE) is part of a group of air leak syndromes, characterized by air leaking into the pulmonary tissue. ${ }^{1,2}$ The occurrence of PIE is attributed to the effects of positive pressure ventilation and poorly compliant lungs. $^{3,4}$ The incidence of spontaneous air leak syndromes in premature infants is approximately 1 to $2 \%$. There are a few cases of spontaneous PIE in patients on continuous positive airway pressure (CPAP), ${ }^{5-7}$ with higher incidence in ventilated low birth weight infants, reported to be as high as $33 \%$ in this group. ${ }^{8,9}$

PIE occurs as air escapes from the small airway into the pulmonary interstitium, it can dissect along the bronchovascular bundles and radiate outward through the periphery of the lung to visceral pleura and then to the pleural space resulting in pneumothorax. The interstitial air can also pass through the lung hilus and soft tissue into the mediastinum, pericardium, or subcutaneous tissue. ${ }^{10}$ Such leakage leads to the development of air trapping cyst clusters which compress the perivascular bundles, generating a decrease in the pulmonary competency. ${ }^{3}$ Compression of remaining healthy lung areas causes atelectasis and impairs gas exchange. ${ }^{11}$ The degree of air trapping and requirement for high ventilation pressure affect systemic venous return and right-ventricular outflow, Pulmonary hypertension then contributes to impaired oxygenation. ${ }^{12,13}$ PIE may involve only one lobe, one lung, or more usually both lungs. ${ }^{2}$ Radiologically, PIE appears as lacelike lucencies in a linear pattern radiating from the pulmonary hilus to the surface of the lung. ${ }^{3}$

Early diagnosis and timely management of PIE are of prime importance. The condition might resolve rapidly in early stage with simple measures, while late recognition or nonjudicious managements may result in life-threatening complications and necessitate more invasive interventions. ${ }^{14,15}$ In the present report, we describe the case of an extremely low birth weight neonate who developed persistent PIE, and several strategies, including lateral decubitus positioning, steroids, and brief periods of selected lung ventilation, were unsuccessful. Five weeks after initial diagnosis, the baby responded favorably to the unusually prolonged selected lung ventilation described below. received

October 9, 2020

accepted after revision

December 8, 2020
DOI https://doi.org/

$10.1055 / \mathrm{s}-0041-1727261$. ISSN 2157-6998.

\footnotetext{
(C) 2021. The Author(s).

This is an open access article published by Thieme under the terms of the Creative Commons Attribution-NonDerivative-NonCommercial-License, permitting copying and reproduction so long as the original work is given appropriate credit. Contents may not be used for commercial purposes, or adapted, remixed, transformed or built upon. (https://creativecommons.org/ licenses/by-nc-nd/4.0/) Thieme Medical Publishers, Inc., 333 Seventh Avenue, 18th Floor, New York, NY 10001, USA
} 


\section{Case Report}

This is a case of a preterm baby boy, twin A, delivered via cesarean section, gestational age of 24 weeks and 4 days, with a birth weight of $840 \mathrm{~g}$. Upon delivery, the baby was intubated, and given a dose of surfactant (subsequent doses of surfactant were given at 20 hours and 44 hours of life). High-frequency mechanical ventilation was started upon admission to the neonatal intensive care unit. A 3-day course of intravenous indomethacin was started on day 3 due to a large patent ductus arteriosus. On day of life 7, the infant developed a right-sided pneumothorax. Thoracentesis was done and chest tube was inserted (removed by 10 days of life). On day of life 9, a chest X-ray (CXR) revealed marked PIE on the left side and minimal amount on the right side. A lung protective strategy consisting of maintaining lower mean airway pressure was adopted. The baby was switched to high-frequency jet ventilation on day of life 15, again maintaining a low mean airway pressure. A 10-day course of dexamethasone (DART protocol) was started on day 20 to facilitate planned extubation ${ }^{16}$; however, this was unsuccessful. Conservative strategies for PIE management, including decreasing ventilator settings as much as possible, lateral decubitus position, and placing a firm object beneath the left side of the chest (Z-flow mattress or rolled towel), were unsuccessful. In view of worsening left-sided PIE and rightsided atelectasis (-Fig. 1A), selective right lung ventilation was done on day 22 for 6 hours. Follow-up CXR showed improvement of the right-side atelectasis but the left-sided overexpansion had minimal improvement. Right-sided atelectasis recurred within 24 of hours of pulling the endotracheal tube (ETT) back to midtrachea, conservative strategies for PIE management were continued hoping the left lateral decubitus would help with the right-sided atelectasis.
Subsequent CXR showed significant overexpansion of the left lung that crossed over to the right side and compressed the right lung with blood gases showing respiratory acidosis. On day 24, The ETT was pushed in to again selectively ventilate the right lung, with follow-up CXR every 12 hours and close monitoring of blood gases. Soon after the oxygen requirement decreased, and the blood gases improved dramatically. The ETT was kept in the right side for 2 days. The infant subsequently developed a right-sided pneumothorax and a chest tube was inserted that was removed after 24 hours. Follow-up CXR showed improvement of the right-sided pneumothorax and right-side atelectasis with mild improvement of the left-side overexpansion. The ETT was again positioned in the midtrachea, and unfortunately, the left-sided overexpansion and right-sided atelectasis worsened.

By 28 days of age, follow-up CXR showed persistent leftsided overexpansion, with respiratory acidosis and increasing oxygen requirement. The ETT was pushed in again to the right main bronchus and kept there for 3 days. The ETT was pulled back above the carina, and the patient was started on synchronized neurally adjusted ventilatory assist ventilation with a positive end expiratory pressure (PEEP) of 8. Left lung hyperinflation was still present on CXR ( -Fig. 1C), so the PEEP was subsequently decreased to 6 and the infant was started on 3-day course of hydrocortisone. Consultation was obtained with pulmonology; pediatric surgery; and ear, nose, and throat; the team's decision was to utilize all possible conservative measures before surgical intervention. CXR at 34 days of age showed massive hyper expansion of the left lung. The fourth round of selective lung ventilation was started, with the baby switched from synchronized neurally adjust ventilatory assist to synchronized intermittent mandatory ventilation with PEEP of $4 \mathrm{~mm} \mathrm{Hg}$, peak inspiratory pressure of $22 \mathrm{~mm}$
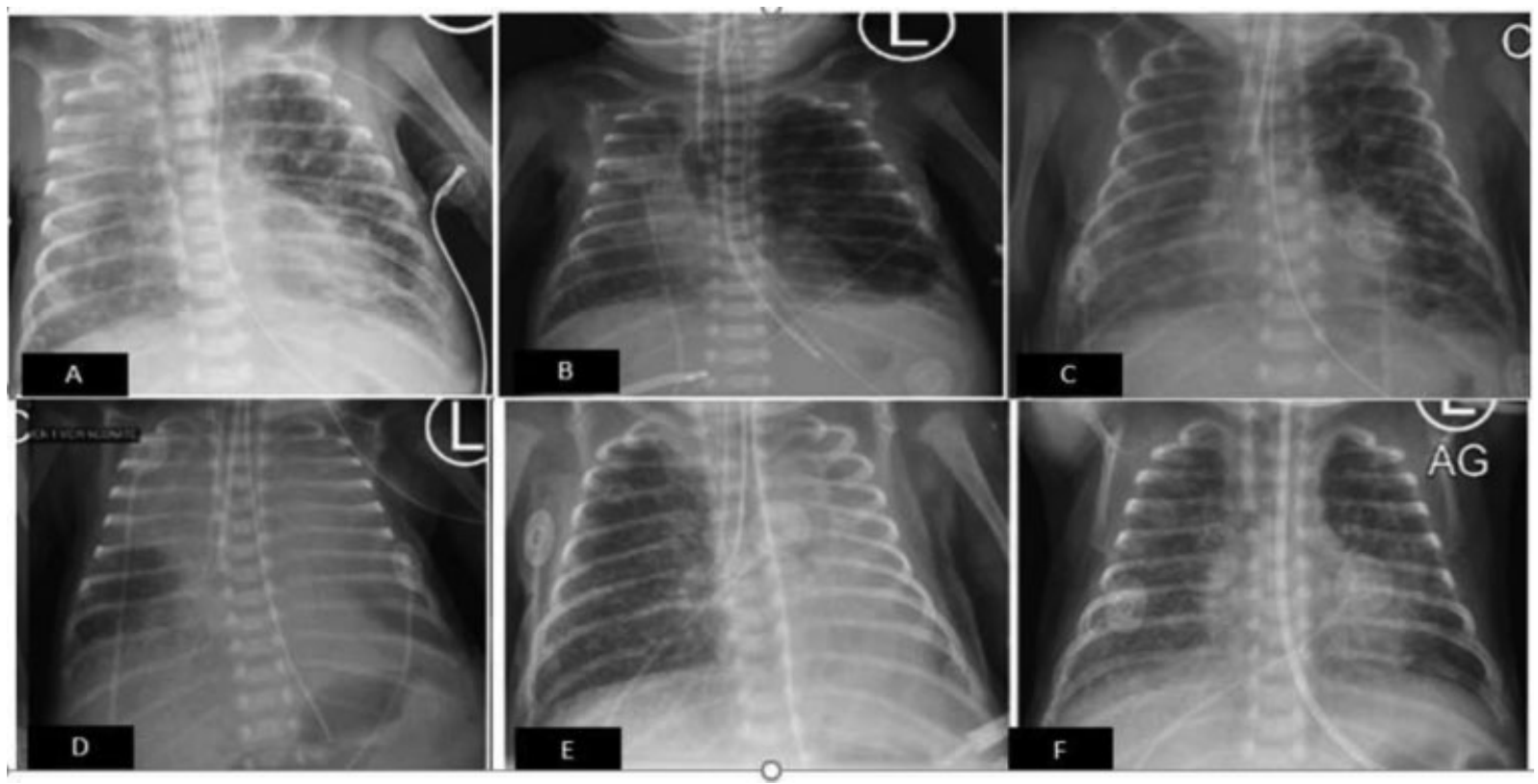

Fig. 1 Chest X-ray: (A) before the first trial of selective right lung ventilation. (B) Before the second trial of selective right lung ventilation. (C) After 3 days (third trial) of right sided ventilation. (D) After 5 days (fourth trial) of right sided ventilation. (E) After 2 weeks of right-sided ventilation. (F) After 1 day of extubation. 
$\mathrm{Hg}$, and inspiratory time of 0.35 with a permissive hypercapnia strategy, in which we overlooked arterial $\mathrm{PaCO}_{2}$ below 70 and $\mathrm{pH}$ above 7.3 (capillary $\mathrm{PaCO}_{2}$ below $80 \mathrm{~mm} \mathrm{Hg}$ and $\mathrm{pH}$ above 7.25 were disregarded also). The respiratory plan was to continue selective right-side ventilation for 2 weeks with very low PEEP, keeping the right side up. To avoid right lung collapse, three cycles daily ( 8 hours each) with PEEP of $4 \mathrm{~mm}$ $\mathrm{Hg}$ for 6 hours and PEEP of 6 for 2 hours. Blood gases were obtained at every 8 hours, and CXR was checked at every 12 hours for 1 week then daily and as needed for the second week. At age of 40 days, CXR showed increased right basilar lung atelectasis with diffuse left lung atelectasis and right upper lobe volume loss. At age of 42 days, CXR showed right upper lobe opacity/collapse, the ETT was pulled back by $0.25 \mathrm{~cm}$ to improve ventilation to the right upper lobe. The ETT tip position was checked periodically to make sure it was persistently in the right main stem bronchus.

DART protocol was restarted at age of 47 days. The ETTwas pulled back to the mainstem bronchus at age of 48 days for 1 hour then the infant was extubated to noninvasive neurally adjusted ventilatory assist mode, with PEEP of 4 . The next day, CXR showed even lungs expansion (-Fig. 1F). On day 52, the baby was weaned to nasal CPAP, then to high-flow nasal cannula at the age of 56 days, and eventually to room air at the age of 119 days. His subsequent clinical course included two surgical interventions requiring reintubation and rapid extubation back to nasal cannula support without reappearance of the left lung overexpansion. He also contracted a viral infection, again, without recurrence of his left lung overexpansion.

The infant was discharged home without oxygen support on day of life 134. He has had several follow-up visits since discharge and is in a good health, breathing comfortably on room air, tolerating on demand oral feeding, and gaining adequate weight.

\section{Discussion}

PIE is a radiographic and pathological diagnosis with a characteristic computed tomography (CT) finding of central lines and dots surrounded by radiolucency in patients with persistent PIE. ${ }^{3,4,17}$ The prognosis of PIE is variable. It can completely resorb, or it can decompress into adjacent spaces. Some infants may develop chronic lobar emphysema which may require surgical lobectomy. The early appearance of PIE ( $<48$ hours after birth) is associated with increased mortality which may reflect the severity of the underlying parenchymal disease. The reported mortality rate associated with PIE ranges from 24 to up to $67 \%{ }^{8,15,18-22}$ Carefully monitoring the peak inspiratory pressure during manual ventilation and during resuscitation in the delivery room, early surfactant treatment in premature infants instead of rescue therapy, reducing the inspiratory time, and/or decreasing peak inspiratory pressure along with adjusting the PEEP just enough to stent the airway are known strategies to decrease the incidence of PIE. ${ }^{15,21-27}$

Different treatment modalities have been used to manage PIE with variable success. In different case studies, PIE resolved after lateral decubitus positioning for 48 hours to 6 days with minimal recurrence and a low failure rate; it has also been used successfully for patients with bilateral PIE when one side is more significantly affected, ${ }^{28,29}$ we tried this multiple time during the course of the disease with no improvement. Another successful treatment for unilateral or severe localized PIE is selective intubation of the contralateral bronchus to decompress the overdistended lung. ${ }^{30,31}$ We also tried this multiple times and for variable durations with partial and transient improvement. Potential complications of selective ventilation include atelectasis in the affected lung, hypoventilation or hypoxemia, hyperinflation of the intubated lung, and right upper lobe collapse when intubating the right lung as was encountered in our case. $^{30,31}$ Despite the potential risks, selective bronchial intubation is a desirable alternative to lobectomy in a patient with persistent, severe, localized PIE that is refractory to conservative management, like in our case. If tolerated, this procedure should be attempted before any surgical intervention. ${ }^{30,31}$ Also, studies have shown that high frequency ventilation is safe and more effective than rapid-rate conventional ventilation in the treatment of PIE. ${ }^{32,33}$ Our baby was on oscillatory ventilation then jet ventilation for a considerable amount of time without resolution or improvement of the overdistension during the course of the disease.

It is difficult to establish clear guidelines for surgical intervention in PIE. Lobectomy should be the last resort treatment for the small number of patients with localized PIE in whom spontaneous regression is not occurring and after exhaustion of all medical strategies. ${ }^{34,35}$ In our case, positioning was tried multiple times, steroids (dexamethasone and hydrocortisone) were given, selective intubation was tried four times (6 hours, 2 days, 3 days, and 2 weeks) with the prolonged right mainstem intubation leading to the resolution of the problem. After successfully deflating the left lung, the more normal radiographic appearance and function persisted despite need for several intubations and an intercurrent viral infection suggests complete healing of the left lung pathology. To our knowledge, this is the longest duration ever reported for selective lung ventilation to treat PIE. It required monitoring the baby's vitals, oxygen requirement, work of breathing, blood gases, and chest X-rays regularly but allowed us to salvage the left lung.

\section{Conclusion}

PIE is a potentially life-threatening condition and is more common in preterm newborn and low birth weight infants exposed to high pressure mechanical ventilation. Early recognition and treatment are fundamental. Conservative treatments are effective in most cases and should be considered prior to surgical intervention. Very prolonged single lung ventilation, if tolerated, should be considered as part of the conservative management options.

\section{Funding}

None. 
Conflicts of Interest

None declared.

\section{References}

1 Dembinski J, Heep A, Kau N, Knöpfle G, Bartmann P. CT imaging of pulmonary lobar interstitial emphysema in a spontaneous breathing preterm infant. Am J Perinatol 2002;19(06):285-290

2 Sheldon BK. Complications: bronchopulmonary dysplasia, air leak syndromes and retinopathy of prematurity. In: Goldsmith JP, Karotkin EH, eds. Assisted Ventilation of the Neonate. 3rd edition. Philadelphia, PA: WB Saunders; 1996:327-352

3 Agrons GA, Courtney SE, Stocker JT, Markowitz RI. From the archives of the AFIP: Lung disease in premature neonates: radiologic-pathologic correlation. Radiographics 2005;25(04):1047-1073

4 Rao J, Hochman MI, Miller GG. Localized persistent pulmonary interstitial emphysema. J Pediatr Surg 2006;41(06):1191-1193

5 Berk DR, Varich LJ. Localized persistent pulmonary interstitial emphysema in a preterm infant in the absence of mechanical ventilation. Pediatr Radiol 2005;35(12):1243-1245

6 Gessler P, Toenz M, Gugger M, Pfenninger J. Lobar pulmonary interstitial emphysema in a premature infant on continuous positive airway pressure using nasal prongs. Eur J Pediatr 2001; 160(04):263-264

7 Gürakan B, Tarcan A, Arda IS, Coşkun M. Persistent pulmonary interstitial emphysema in an unventilated neonate. Pediatr Pulmonol 2002;34(05):409-411

8 Greenough A, Dixon AK, Roberton NR. Pulmonary interstitial emphysema. Arch Dis Child 1984;59(11):1046-1051

9 Crosswell HE, Stewart DL. Special feature: radiological case of the month. Pulmonary interstitial emphysema in a nonventilated preterm infant. Arch Pediatr Adolesc Med 2001;155(05):615-616

10 Malkin S, Binns BAO. A case of spontaneous pneumothorax and pneumomediastinum in the newborn. Can Med Assoc J 1962;86 (04):183-185

11 Stocker JT, Madewell JE. Persistent interstitial pulmonary emphysema: another complication of the respiratory distress syndrome. Pediatrics 1977;59(06):847-857

12 Greenough A, Mildner AD. Pulmonary disease of the newborn. Acute respiratory disease In: Rennie RM, ed. Roberton's Textbook of Neonatology. 4th ed. Philadelphia, PA: Elsevier; 2005:468-553

13 Harris TR, Wood BR. Physiological principles. In: Goldsmith JP Karotkin EH, editors. Assisted Ventilation of the Neonate. 3rd ed. Philadelphia, PA: WB Saunders; 1996:21-68

14 Wilmott R, Bush A, Deterding R, et al. Kendig's Disorders of the Respiratory Tract in Children. 9th ed. Philadelphia, PA: Elsevier; 2018

15 Perea L, Blinman T, Piccione J, Laje P. Bilateral congenital lobar emphysema: staged management. J Pediatr Surg 2017;52(09): 1442-1445 [Medline]

16 Doyle LW, Davis PG, Morley CJ, McPhee A, Carlin JBDART Study Investigators. Low-dose dexamethasone facilitates extubation among chronically ventilator-dependent infants: a multicenter, international, randomized, controlled trial. Pediatrics 2006;117 (01):75-83

17 Donnelly LF, Lucaya J, Ozelame V, et al. CT findings and temporal course of persistent pulmonary interstitial emphysema in neonates: a multiinstitutional study. AJR Am J Roentgenol 2003;180 (04):1129-1133

18 Heneghan MA, Sosulski R, Alarcon MB. Early pulmonary interstitial emphysema in the newborn: a grave prognostic sign. Clin Pediatr (Phila) 1987;26(07):361-365
19 Hart SM, McNair M, Gamsu HR, Price JF. Pulmonary interstitial emphysema in very low birthweight infants. Arch Dis Child 1983; 58(08):612-615

20 Verma RP, Chandra S, Niwas R, Komaroff E. Risk factors and clinical outcomes of pulmonary interstitial emphysema in extremely low birth weight infants. J Perinatol 2006;26(03):197-200

21 Gaylord MS, Thieme RE, Woodall DL, Quissell BJ. Predicting mortality in low-birth-weight infants with pulmonary interstitial emphysema. Pediatrics 1985;76(02):219-224

22 Morisot C, Kacet N, Bouchez MC, et al. Risk factors for fatal pulmonary interstitial emphysema in neonates. Eur J Pediatr 1990;149(07):493-495

23 Thayyil S, Nagakumar P, Gowers H, Sinha A. Optimal endotracheal tube tip position in extremely premature infants. Am J Perinatol 2008;25(01):13-16

24 Toledo Del Castillo B, Gordillo I, Rubio García E, et al. Diffuse persistent pulmonary interstitial emphysema secondary to mechanical ventilation in bronchiolitis. BMC Pulm Med 2016;16(01): 139

25 Aiyoshi T, Masumoto K, Shinkai T, et al. Pulmonary interstitial emphysema due to respiratory syncytial virus infection. Pediatr Int (Roma) 2016;58(09):916-919

26 Stevens TP, Harrington EW, Blennow M, Soll RF. Early surfactant administration with brief ventilation vs. selective surfactant and continued mechanical ventilation for preterm infants with or at risk for respiratory distress syndrome. Cochrane Database Syst Rev 2007;(04):CD003063

27 Donn SM. Assisted ventilation and its complications. Martin RJ, Fanaroff AA, Walsh MC, eds. Fanaroff and Martin's NeonatalPerinatal Medicine: Diseases of the Fetus and Infant. 10th ed. Vol. 2;Philadelphia, PA: Saunders; 2014:1107

28 Bidiwala K, Mimouni F, Lorenz JM, Tsang RC. Lateral decubitus position and pulmonary interstitial emphysema. J Pediatr 1984; 105(05):847-848

29 Cohen RS, Smith DW, Stevenson DK, Moskowitz PS, Graham CB. Lateral decubitus position as therapy for persistent focal pulmonary interstitial emphysema in neonates: a preliminary report. J Pediatr 1984;104(03):441-443

30 Chalak LF, Kaiser JR, Arrington RW. Resolution of pulmonary interstitial emphysema following selective left main stem intubation in a premature newborn: an old procedure revisited. Paediatr Anaesth 2007;17(02):183-186

31 Rent SM, Donn SM. Treatment of Severe Unilateral Pulmonary Interstitial Emphysema in a Preterm Infant. Clin Case Rep Int. 2017;1:1019

32 Keszler M, Donn SM, Bucciarelli RL, et al. Multicenter controlled trial comparing high-frequency jet ventilation and conventional mechanical ventilation in newborn infants with pulmonary interstitial emphysema. J Pediatr 1991;119(1 Pt 1):85-93

33 Squires KA, De Paoli AG, Williams C, Dargaville PA. High-frequency oscillatory ventilation with low oscillatory frequency in pulmonary interstitial emphysema. Neonatology 2013;104(04): 243-249

34 Ahluwalia JS, Rennie JM, Wells FC. Successful outcome of severe unilateral pulmonary interstitial emphysema after bi-lobectomy in a very low birthweight infant. J R Soc Med 1996;89(03): 167P-168P

35 Jassal MS, Benson JE, Mogayzel PJ Jr. Spontaneous resolution of diffuse persistent pulmonary interstitial emphysema. Pediatr Pulmonol 2008;43(06):615-619 